psychiatrists have an ethical duty to protect third parties who may be important informants and thus to scan records before they are made available to the prisoner

\section{Psychiatric reports}

\section{(a) The purpose of this report}

Many reports will be regarded by prisoners as about them, but for the benefit of the prison or legal system.

Before interviewing a prisoner for a report, a psychiatrist has the ethical responsibility to obtain the informed consent of the prisoner, after explaining to him/her the purpose of the assessment and to whom the report will be sent. The prisoner should be informed of his/her rights to refuse to talk to the psychiatrist.

\section{(b) Professional expertise}

The preparation of a psychiatric report on a prisoner should only be done by a properly qualified psychiatrist, or by a psychiatric trainee under supervision. Consultants have an ethical responsibility to provide assessments, if requested to do so, for the patients who are already known to them, and/or are living in their catchment area.

\section{"Whistle-blowing"}

All medical staff in the National Health Service are not only entitled, but have a duty, to disclose situations which they believe to be damaging to the standards of care for their patients. These could be inadequate facilities, or the behaviour of a member of the staff. Exactly the same opportunities for disclosure should be available to psychiatrists working under contract to the prison service. As in the NHS, they should be made aware of the appropriate channels for disclosure or complaint but if these are exhausted and their concerns remain, they are entitled to take them outside the local system, to their own professional organisations and to the professional or ordinary press. On no account should the Official Secrets Act be used to "gag" staff if they are complaining about standards of care or of other practices which they regard as unethical.

The College - and the BMA - should listen sympathetically to "whistle-blowers" and support them and, if thought appropriate, take up their complaints on their behalf.

\section{Audit and research}

In accordance with NHS good practice, consultants should expect to participate in regular medical audit of their work in prisons.

High quality psychiatric research is essential to the future development of the Prison Medical Service. Certain ethical issues arise in this work, particularly concerninginformed consent. Ethical scrutiny of such research is therefore essential, as for all research projects on human subjects. Once approved, research should be allowed to proceed to completion and publication, following the same procedures as those applying to any other NHS or academic research study. Psychiatric research in prisons should not rely entirely on funds provided by the Home Office.

Dr J.L.T. BIRLEY Chairman

Special Committee on Unethical Psychiatric Practices

Approved by Council of the Royal College of Psychiatrists

14 January 1992

\title{
Administration of radionuclides for research purposes
}

The Executive and Finance Committee has recently discussed the issue of the administration of radionuclides to patients for research purposes. The Committee wishes to draw to members' attention the fact that, in accordance with the Medicines (administration of radioactive substances) Regulations 1978, the administration of radionuclides requires an ARSAC (Administration of Radioactive Substances
Advisory Committee) Research Certificate. The Regulation states that separate certification is required for the administration of these substances for the purpose of diagnosis, treatment and research.

Professor AnN Gath Registrar 